\title{
Effect of biochar on soil characteristics of Yellow River Delta coastal wetland, China
}

\author{
Yufei $\mathrm{CaO}^{1,2}$, Xiaotong $\mathrm{Li}^{1,2}$, Xiao Wang ${ }^{1,2^{*}}$ \\ ${ }^{1}$ Institute of Coastal Environmental Pollution Control, Key laboratory of Marine Environment and Ecology, Ministry of Education, \\ College of Environmental Science and Engineering, Ocean University of China, Qingdao 266100, China \\ ${ }^{2}$ College of Environmental Science and Engineering, Ocean University of China, Qingdao 266100, China
}

\begin{abstract}
Coastal wetland soil quality has been threatened due to anthropogenic disturbance and thus an effective measure is urgent to be used to reclaim the degraded wetland soils. Biochar is a promising carbonaceous material that has been proved an effective strategy for soil carbon sequestration and soil remediation. However, few researches have paid attention to effect of biochar on soil characteristics under rainfall conditions in coastal wetland. Thus, we conducted a leaching experiment to explore the effect of biochar on soil $\mathrm{pH}, \mathrm{EC}, \mathrm{CEC}, \mathrm{Ex}-\mathrm{Na}^{+}$and ESP. The results showed that biochar addition significantly decreased soil pH, EC, Ex-Na ${ }^{+}$and ESP, and increased soil CEC. Our findings showed that biochar could be a promising soil remediation in degraded coastal wetland ecosystems with multiple benefits.
\end{abstract}

\section{Introduction}

Coastal wetland, referred as "blue carbon", could sequester 13-17.2 $\mathrm{Pg}$ of carbon, acting as a natural carbon sink, which has been widely concerned [1]. Yet 'blue carbon' has been suffering dramatic loss due to anthropogenic disturbance, such as land type change, oil pollution, resulting in a potential threat to coastal wetland ecosystems [2]. Consequently, an effective measure is urgent to be used to reclaim the degraded wetland soils. Traditional tools such as chemical measures and water irrigation are expensive and less effective for elevating soil carbon sequestration.

Biochar is solid carbonaceous residue pyrolyzed from biomass under anaerobic conditions [3]. Biochar has been widely proposed as one of promising measures to promote soil carbon sequestration capacity due to its recalcitrant structure and resistance to various environmental changes [4]. In addition to it, biochar could improve soil quality and enrich soil nutrients via sorption due to its high pore volume, large surface area and negative surface charge [5]. Some studies showed that biochar application to soil significantly decreased soil salinity and improved plant growth [6]. These results showed that biochar could effectively affect soil characteristics. However, few studies paid attention to the influence of biochar on soil characteristics under periodic rainfall conditions.

To explore effect of biochar on soil characteristics under rainfall conditions, we collected soil samples from Yellow River Delta, a typical coastal wetland, and conducted a leaching experiment for three months to simulate periodic rainfall. We hypothesized that biochar could decrease soil $\mathrm{pH}, \mathrm{EC}$, exchangeable $\mathrm{Na}^{+}$and increase soil CEC.

\section{Materials and methods}

\subsection{Soil and biochar}

The surface soils $(0-20 \mathrm{~cm})$ and subsoils $(30-60 \mathrm{~cm})$ were collected at random from Yellow River Delta Wetland Nature Reserve $\left(37^{\circ} 51^{\prime} \mathrm{N}, 119^{\circ} 00^{`} \mathrm{E}\right)$. The soil samples were air dried, ground to pass through a $2 \mathrm{~mm}$ sieve for further experiment. Biochar was pyrolyzed from corn cob at $550^{\circ} \mathrm{C}$ for $3 \mathrm{~h}$.

\subsection{Soil leaching experiment}

Biochar was added to soil (topsoil and subsoil) at rates of $0 \%$ and $3 \%$, and mixed thoroughly. The first layer of soil column $(0-20 \mathrm{~cm})$ was filled with topsoil and the second layer was crowded with subsoil $(20-60 \mathrm{~cm})$. The experiment was set in two treatments that depended on whether biochar was added. The two treatments were replicated in three times and soil characteristics of all treatments were tested before and after the leaching experiment, named as (1) CK-B; (2) CK-A; (3) BC-B; (4) BC-A.

The leaching device was made of plexiglass. The inner diameter of the device was $6 \mathrm{~cm}$, the height was $70 \mathrm{~cm}$ and the diameter of water outlet hole was $5 \mathrm{~mm}$. The bottom of device was covered with a layer of nylon and dry quartz sand with thickness of $3 \mathrm{~cm}$ to prevent leakage of soil particles. After soil was filled, quartz

\footnotetext{
* Corresponding author: wangxiao5120@ouc.edu.cn
} 
sand with a thickness of about $3 \mathrm{~cm}$ was spread on soil to prevent uneven water flow.

All treatments were kept in the same conditions at room temperature for three months. During the incubation, a hanging bottle infusion was set to slowly drip $200 \mathrm{ml}$ ultrapure water to simulate precipitation. After the experiment, soil columns were divided into 6 layers every $10 \mathrm{~cm}$ depth. All soil samples were tested $\mathrm{pH}, \mathrm{EC}, \mathrm{CEC}$, Exchangeable-Na+ and ESP.

\subsection{Samples analysis}

The $\mathrm{pH}$ of samples was determined by $\mathrm{pH}$ meter and $\mathrm{EC}$ was determined by portable conductivity meter. CEC of soil samples was measured by ammonium acetate method. Soil samples were treated with $\mathrm{NH}_{4} \mathrm{OAc}(\mathrm{pH}$ 7.0) to replace all base cations with ammonium ions. The adsorbed $\mathrm{NH}_{4}{ }^{+}$was replaced with $\mathrm{K}^{+}$from sorption sites. The concentration of $\mathrm{NH}_{4}^{+}$in solution was measured to calculate $\mathrm{CEC}$ by capturing $\mathrm{NH} 3$ in saturated $\mathrm{H}_{3} \mathrm{BO}_{3}$ solution and titrated with $0.1 \mathrm{M} \mathrm{HCl}$ in the presence of indicators. Exchangeable- $\mathrm{Na}^{+}$of samples was measured by flame photometry method. ESP was determined by ratio of exchangeable- $\mathrm{Na}^{+}$and CEC.

\subsection{Statistical analysis}

All results were expressed as mean values. Significant differences between treatments were determined by oneway analysis of variance with Duncan's multiple range test $(\mathrm{P}=0.05)$ and Statistical Product and Service Solutions Software 20.0 (SPSS 20.0).

\section{Results and discussion}

\subsection{Effect of biochar on soil pH}

The $\mathrm{pH}$ of soil decreased with increasing soil depths and biochar significantly decreased $\mathrm{pH}$ of soil (Fig.1). Biochar significant decreased $\mathrm{pH}$ of soil by $0.05-0.25$ at depth of $0-50 \mathrm{~cm}$. After the leaching, $\mathrm{pH}$ of soil decreased significantly, which indicated that rainfall could significantly affect the concentrations of alkaline ions. The results were different from some researches in which biochar increased soil $\mathrm{pH}$ [7]. It was possible that biochar improved soil aeration facilitating more alkaline ions dissolution and thus offset possible promotion effect. The results showed that biochar could promote soil aeration so as to affect $\mathrm{pH}$ of soil.

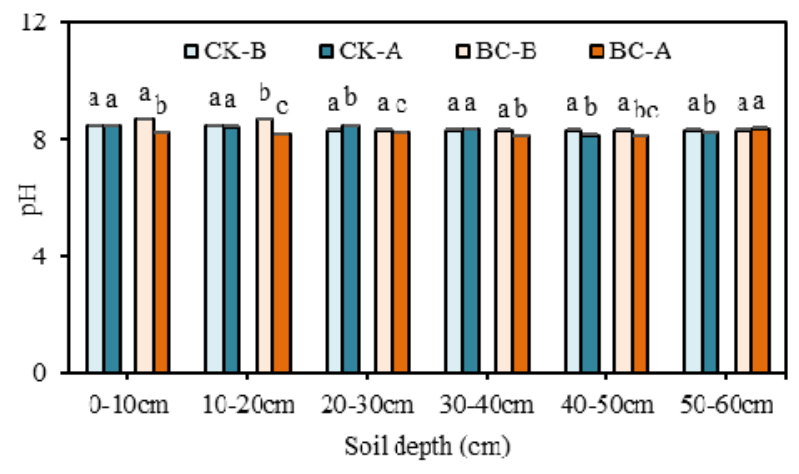

Fig. 1. Effect of biochar on soil $\mathrm{pH}$ among treatments before and after the leaching experiment. Error bars represent standard deviations of the means $(n=3)$. Different small letters indicate significant difference among treatments $(\mathrm{p}<0.05)$

\subsection{Effect of biochar on soil EC}

The EC of soil increased at depth of $0-50 \mathrm{~cm}$ and decreased sharply at depth of $50-60 \mathrm{~cm}$ with increasing soil depths and biochar significant increased EC of soil (Fig.2). Compared to treatments without biochar, biochar addition significantly increased soil $\mathrm{EC}$ by $1-5 \mathrm{mS} \mathrm{cm}^{-1}$, it indicated that cations such as $\mathrm{K}^{+}, \mathrm{Ca}^{2+}$ could be released from biochar and thus increased EC of soil. After the leaching experiment, EC of the soil samples significantly decreased, which was similar to the changes of soil $\mathrm{pH}$. It was possible that water flow eroded soil cations and more cations accumulated at depth of 30$40 \mathrm{~cm}$ may result in increase of EC. These results showed that biochar could release cations to affect soil characteristics such as EC, which could affect microbial activity and plant growth [8].

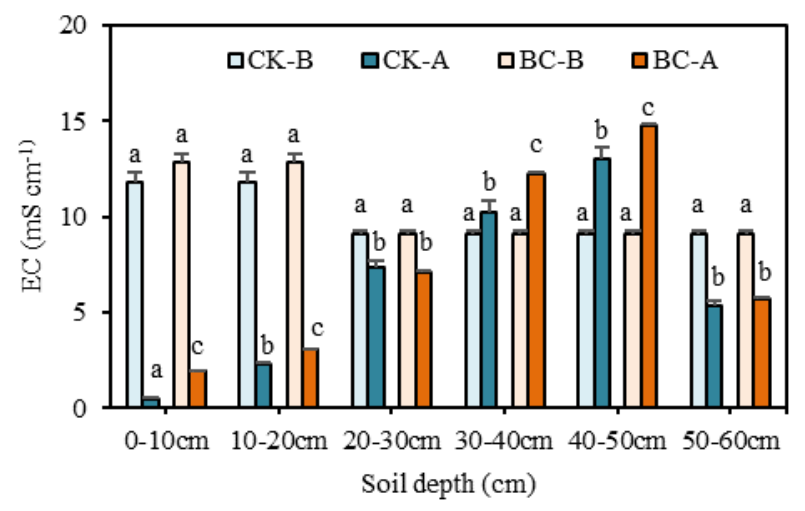

Fig. 2. Effect of biochar on soil EC among treatments before and after the leaching experiment. Error bars represent standard deviations of the means $(n=3)$. Different small letters indicate significant difference among treatments $(\mathrm{p}<0.05)$.

\subsection{Effect of biochar on soil CEC}

The CEC of soil increased at depth of $0-40 \mathrm{~cm}$ and decreased at depth of $40-60 \mathrm{~cm}$ with increasing soil depths, and biochar significant increased CEC of soil (Fig.3). After the leaching experiment, CEC of soil samples increased on average of $12.37 \%$ in treatments without biochar addition, soil CEC increased on average 
of $21.32 \%$. The CEC of soil increased at depth of 0 $40 \mathrm{~cm}$ may attribute to upper cations accumulation and the CEC of soil decreased at depth of $40-60 \mathrm{~cm}$ could result from leaching. Biochar significantly increased soil CEC by 3\%-31\%, which indicated that biochar improved the ability of soil to adsorb, exchange and retain cations [9]. In addition to it, biochar increased soil CEC at depth of $40-60 \mathrm{~cm}$, which indicated that biochar could affect soil characteristics of subsoil and potentially improved soil qualities at various soil layers [10].

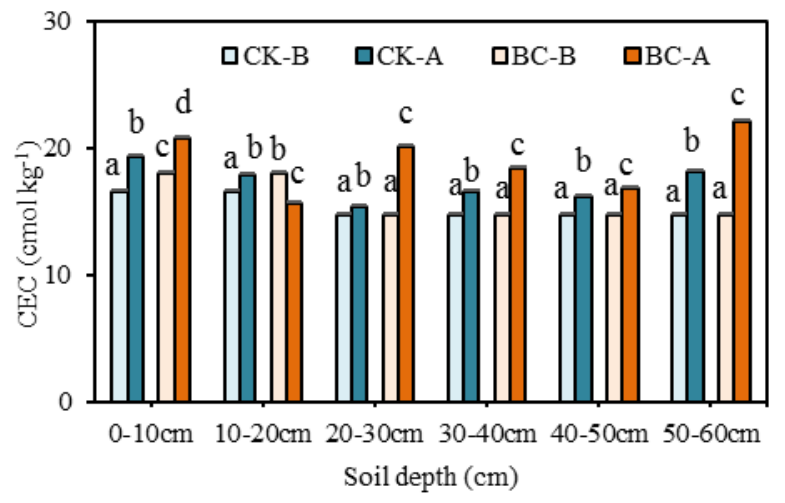

Fig. 3. Effect of biochar on soil CEC among treatments before and after the leaching experiment. Error bars represent standard deviations of the means $(n=3)$. Different small letters indicate significant difference among treatments $(\mathrm{p}<0.05)$.

\subsection{Effect of biochar on soil Ex-Na+}

The Ex- $\mathrm{Na}^{+}$of soil decreased at depth of $0-50 \mathrm{~cm}$ and increased sharply at depth of $50-60 \mathrm{~cm}$ and biochar significantly decreased Ex-Na+ of soil (Fig.4). After the leaching experiment, $\mathrm{Ex}-\mathrm{Na}^{+}$of soil significantly decreased on average of $25.71 \%$ in treatments without biochar addition. The results were consistent with changes of soil CEC, which indicated that water flow eroded soil cations and affect the retention of nutrition. Biochar significantly decreased soil $\mathrm{Ex}-\mathrm{Na}^{+}$on average of $38.96 \%$ and decreased by $40.51 \%$ at depth of $0-50 \mathrm{~cm}$, compared to treatments without biochar addition, which indicated that biochar effectively decreased soil $\mathrm{Ex}-\mathrm{Na}^{+}$ and improved soil qualities. Our results were consistent with some studies that showed biochar effectively decrease soil $\mathrm{Ex}^{-\mathrm{Na}^{+}}$via sorption due to lots of adsorption sites on biochar surface and high surface areas [11].

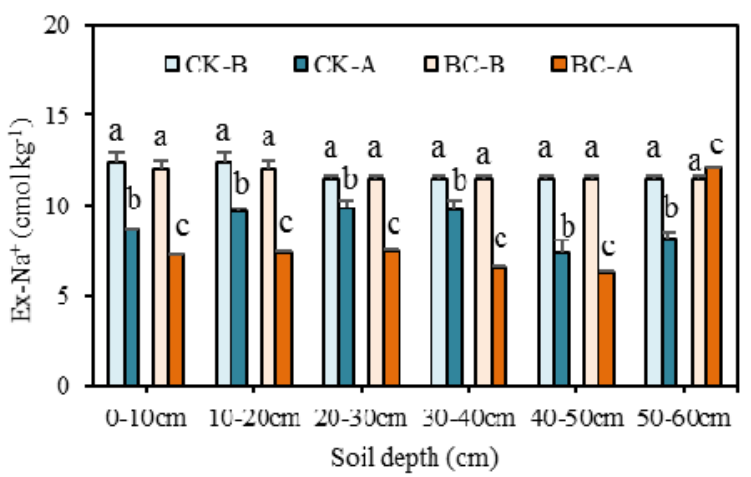

Fig. 4. Effect of biochar on soil Ex-Na ${ }^{+}$among treatments before and after the leaching experiment. Error bars represent standard deviations of the means $(n=3)$. Different small letters indicate significant difference among treatments $(p<0.05)$.

\subsection{Effect of biochar on soil ESP}

Biochar significantly decreased soil ESP and the ESP of soil decreased significantly by $17.26-54.26 \%$ compared to treatments without biochar addition after the leaching (Fig.5). Biochar significantly decreased soil ESP on average of $12.50 \%$ before the leaching experiment and ESP decreased by $25.12 \%$ after the leaching. Besides it, water flow significantly decreased soil ESP on average of $13.17 \%$ and the results indicated that water irrigation measures could be helpful to remediate coastal wetland soil but were less effective than biochar due to higher expense. The effect of biochar on soil ESP was consistent with Ex- $\mathrm{Na}^{+}$concentrations in soil samples. Biochar decreased soil ESP due to decrease of changes of Ex-Na+ and increase of soil CEC, which could be contributed to the adsorption of biochar on soil $\mathrm{Na}^{+}$[12]. Decreased ESP may promote plant growth, facilitate microbial activity, improve enzymes activities and increase primary productivity in graded coastal wetland ecosystems.

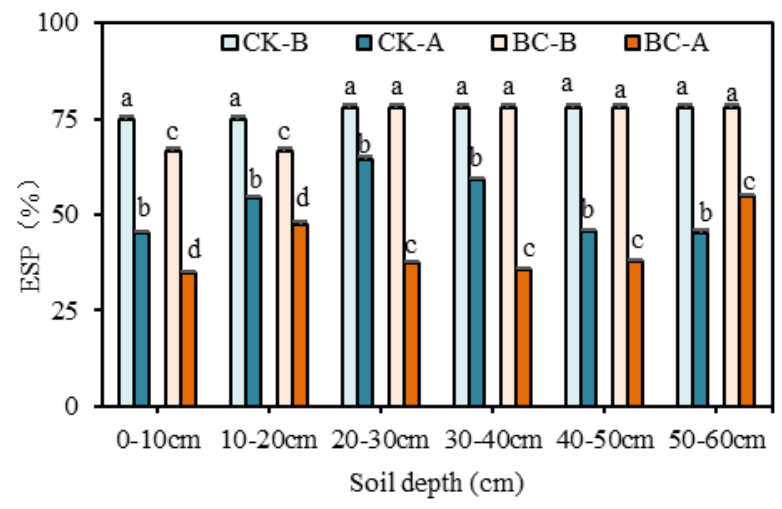

Fig. 5. Effect of biochar on soil ESP among treatments before and after the leaching experiment. Error bars represent standard deviations of the means $(n=3)$. Different small letters indicate significant difference among treatments $(\mathrm{p}<0.05)$. 


\section{Conclusion}

We conducted a leaching experiment for three months to explore the effect of biochar on soil characteristics under simulated field conditions. Biochar could decrease soil $\mathrm{pH}, \mathrm{EC}, \mathrm{Ex}-\mathrm{Na}^{+}$and ESP. In addition to, biochar could increase soil CEC. These results demonstrated that biochar implication to coastal wetland soil could effectively improve soil characteristics, which could be beneficial to improve primary productivity and promote plant growth. The results provided perspectives that biochar could be a promising soil remediation in degraded coastal wetland ecosystems with multiple benefits.

\section{Acknowledgements}

This study was supported by the National Natural Science Foundation of China (41573089).

\section{References}

1. M.S. Fennessy, Global Environ Change, 129, 255261 (2014)

2. E. Mcleod, G.L. Chmura, S. Bouillon, R. Salm, M. Bjork, C.M. Duarte, C.E. Lovelock, W.H. Schlesinger, B.R. Silliman, Front. Ecol. Environ, 9, 552-560 (2011)

3. C. Santin, S.H. Doerr, E. Kane, C. Masiello, M. Ohlson, J.M. Rosa, C. Preston, T. Dittmar, Global. Change. Biol, 22, 76-91 (2016)

4. J. Six, K. Paustian, Soil. Biol. Biochem, 68 (2014)

5. Z.M. Chen, B.L. Chen, D. Zhou, W.Y. Chen, Environ. Sci. Technol, 46, 12476-12483 (2012)

6. S.C. Thomas, S. Frye, N. Gale, M. Garmon, R. Launchbury, N. Machado, S. Melamed, J. Murray, A. Petroff, C. Winsrough, J. Environ. Manage, 129, 62-68 (2013)

7. J.H. Yuan, R.K. Xu, H. Zhang, Bioresour. Technol, 102, 3488-3497 (2011)

8. M.M. Masud, J.Y. Li, R.K. Xu, J. Soil. Sediment, 15, 365-373 (2015)

9. G. Ojeda, S. Mattana, A. Avila, J.M. Alcaniz, Geoderma, 1, 249-250 (2015)

10. S. Abel, A. Peters, S. Trinks, M. Facklam, G. Wessolek, Geoderma, 202, 183-191 (2013)

11. E.H. Tryon, Ecol. Monogr, 18 (2010)

12. G. Xu, Y.C. Lv, J. Sun, H.B. Shao, L.L. Wei, Clean. Soil. Air. Water, 1, 1-6 (2012) 